\title{
Experimental Evaluation for the Microvibration Performance of a Segmented PC Method Based High Technology Industrial Facility Using 1/2 Scale Test Models
}

\author{
Sijun Kim ${ }^{1}$ and Se Woon Choi ${ }^{2}$ \\ ${ }^{1}$ Department of Plant Architectural Engineering, Kyonggi University, Suwon, Gyeonggi-do 16227, Republic of Korea \\ ${ }^{2}$ Department of Architecture, Catholic University of Daegu, Gyeongsan-si, Gyeongbuk 38430, Republic of Korea \\ Correspondence should be addressed to Se Woon Choi; watercloud@cu.ac.kr
}

Received 8 December 2016; Revised 13 January 2017; Accepted 24 January 2017; Published 12 February 2017

Academic Editor: Giada Gasparini

Copyright (C) 2017 Sijun Kim and Se Woon Choi. This is an open access article distributed under the Creative Commons Attribution License, which permits unrestricted use, distribution, and reproduction in any medium, provided the original work is properly cited.

The precast concrete (PC) method used in the construction process of high technology industrial facilities is limited when applied to those with greater span lengths, due to the transport length restriction (maximum length of 15 16 $\mathrm{m}$ in Korea) set by traffic laws. In order to resolve this, this study introduces a structural system with a segmented PC system, and a 1/2 scale model with a width of $9000 \mathrm{~mm}$ (hereafter Segmented Model) is manufactured to evaluate vibration performance. Since a real vibrational environment cannot be reproduced for vibration testing using a scale model, a comparative analysis of their relative performances is conducted in this study. For this purpose, a 1/2 scale model with a width of $7200 \mathrm{~mm}$ (hereafter Nonsegmented Model) of a high technology industrial facility is additionally prepared using the conventional PC method. By applying the same experiment method for both scale models and comparing the results, the relative vibration performance of the Segmented Model is observed. Through impact testing, the natural frequencies of the two scale models are compared. Also, in order to analyze the estimated response induced by the equipment, the vibration responses due to the exciter are compared. The experimental results show that the Segmented Model exhibits similar or superior performances when compared to the Nonsegmented Model.

\section{Introduction}

Microvibrations pose a critical issue in high technology facilities that manufacture products which require precision fabrication, such as semiconductors, LCD, and optical microscopes. This vibration, which occurs during the product manufacturing process, amplifies production errors and causes defects and degradation in product performance. Thus, it is imperative that the vibration performance of (i) equipment and (ii) building structures where equipment which produce vibration-sensitive products is installed be assessed and controlled.

Generally, most manufacturers of vibration-sensitive equipment perform vibration testing on their equipment and provide some level of vibration specifications with their equipment [1]. However, it is common for installed equipment be selected after considering the design and construction of the structure that will support the equipment. Also, as technologies advance with time, there are cases where the original equipment is later replaced by equipment of greater performance. As a result, generic vibration design criteria have been proposed to evaluate the vibration performance of the support structure regardless of the equipment [1-6]. The criteria take the form of a set of one-third octave band velocity spectra labeled vibration criterion curves VC-A through VC$\mathrm{E}$ and are known as the BBN criterion curves [4].

This approach has been utilized in evaluating the vibration performance of various structures [7-10]. Lee et al. [7] analytically performed a microvibration performance assessment of a thin-film transistor liquid crystal display (TFTLCD) factory, constructed of a flat RC slab supported by longspan steel mega trusses, where vibration was generated by automated guided vehicles. Pan et al. [8] conducted vibration performance assessments through analysis and experiments using humans walking as the vibration source, for a biotechnology laboratory with floors supported by long-span RC 


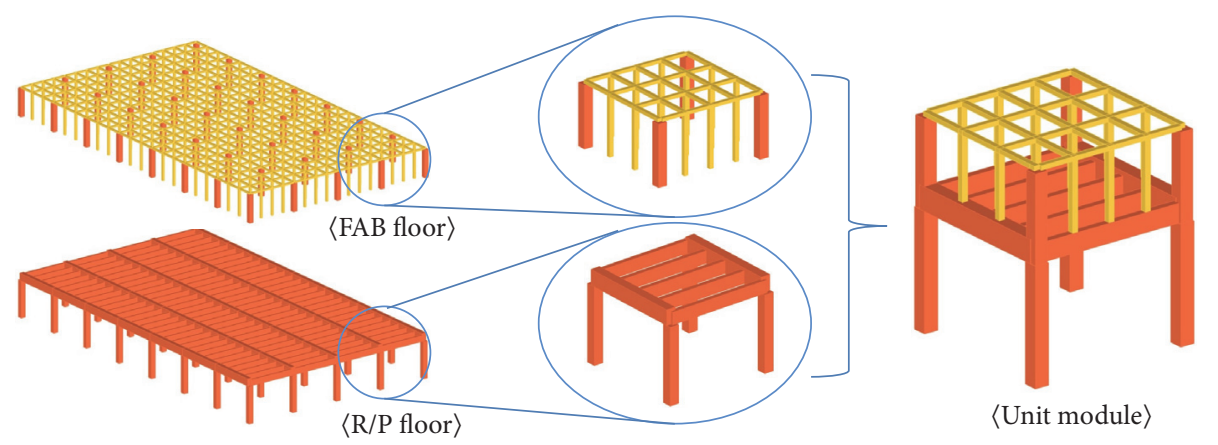

FIGURE 1: High technology industrial facility structure.

beams. Brownjohn et al. [9] performed experimental and analytical modal analysis and in-operation measurements for the evaluation of floor vibration serviceability in a factory building. Brownjohn et al. [9] advises that the vibrationsensitive products are manufactured on the floor with smaller spans is preferable.

The vibration performance of a structure involves an intricate relationship with the stiffness of the structure. Hence, to improve the vibration performance of a structure, increasing the member size can be considered. However, this method has clear limitations, since it results in increased construction costs. As an alternative approach, isolators can be applied rather than increasing the member size, and related studies have been conducted by numerous researchers to determine their effect [10-16].

On the other hand, the proper selection of appropriate structure systems can also enhance the vibration performance of structures. However, the vibration performance of a structure is affected by various structural design factors such as the (i) material (concrete, steel, and composite), (ii) supporting element of the floor (slab on grade, suspended slabs supported by columns), and (iii) floor shape (flat slab, waffle slab, etc.), and therefore the appropriate system needs to be selected by taking into consideration the characteristics of each structural system [2, 17-20].

Up until the mid-1990s, high technology facilities used the cast-in-place reinforced concrete (RC) method to construct their facilities' structure [21]. However, the vertical height of high technology facilities is often more than 8-9 m, so adopting the RC construction method would be uneconomical and lead to longer construction times, due to aerial work, floor posts, and formwork construction. The increase in construction time can be a significant disadvantage due to the rapidly changing nature of the industry, including the available technology and preferences of the consumer. As a result, construction methods employing precast concrete (PC) have been adopted since the mid-1990s [21]. The PC method manufactures structural members in a factory and assembles them onsite, minimizing onsite work and reducing construction times to ensure economic feasibility.

With the increasing size of manufacturing equipment, it becomes necessary to create longer manufacturing line span lengths in recent high technology industrial facilities. However, PC members have to be designed so that they can be transported from the factory where they are manufactured to the construction site. According to the traffic laws of Korea, the maximum length of $\mathrm{PC}$ members for transportation is

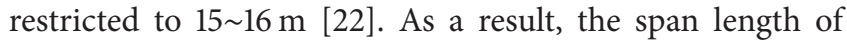
structures constructed using the PC method is generally less than $15 \sim 16 \mathrm{~m}$.

Lee et al. [22] presented a segmented PC beam system for constructing high technology industrial facilities with span lengths greater than $17 \mathrm{~m}$ and performed simulations for verification. The proposed segmented PC beam system used the concept of the Gerber beam [23] to divide the long girder into (i) two-ended cantilevered beams and (ii) a central simple beam placed on top of the two-ended cantilevered beams in order to realize span lengths of $17 \mathrm{~m}$ or greater [22]. Since the vibration performance of the proposed segmented PC method had been verified by using the only simulation results, the experimental verification is required to apply the proposed method to real structures.

This study aims to experimentally evaluate the vibration performance of the segmented PC method which is verified through the simulation. To achieve this goal, the $1 / 2$ scale model (hereafter, the Segmented Model) of high technology industrial facility using of a segmented PC method by Lee et al. [22] is manufactured, and, also, the $1 / 2$ scale model (hereafter, the Nonsegmented Model) of typical high technology industrial facility using of a nonsegmented PC method is manufactured. By applying the same experimental methods to both scale models and comparing the results, the relative vibration performance of the Segmented Model is investigated. Impact testing and harmonic load testing are conducted to compare the natural frequencies, transfer functions, and responses of the two models.

\section{Segmented PC Method Applied to High Technology Industrial Facility Structure}

The structure of the high technology industrial facility dealt with in this study is composed of fabrication (FAB floor) and return plenum (R/P floor) structures as shown in Figure 1, where the entire high technology industrial facility structure is comprised of a two floor structure of unit spans ( 1 span $\times$ 1 span) repeated consecutively. The FAB floor is where the fabrication and production of products occur and the $\mathrm{R} / \mathrm{P}$ floor is where various equipment are installed, including 


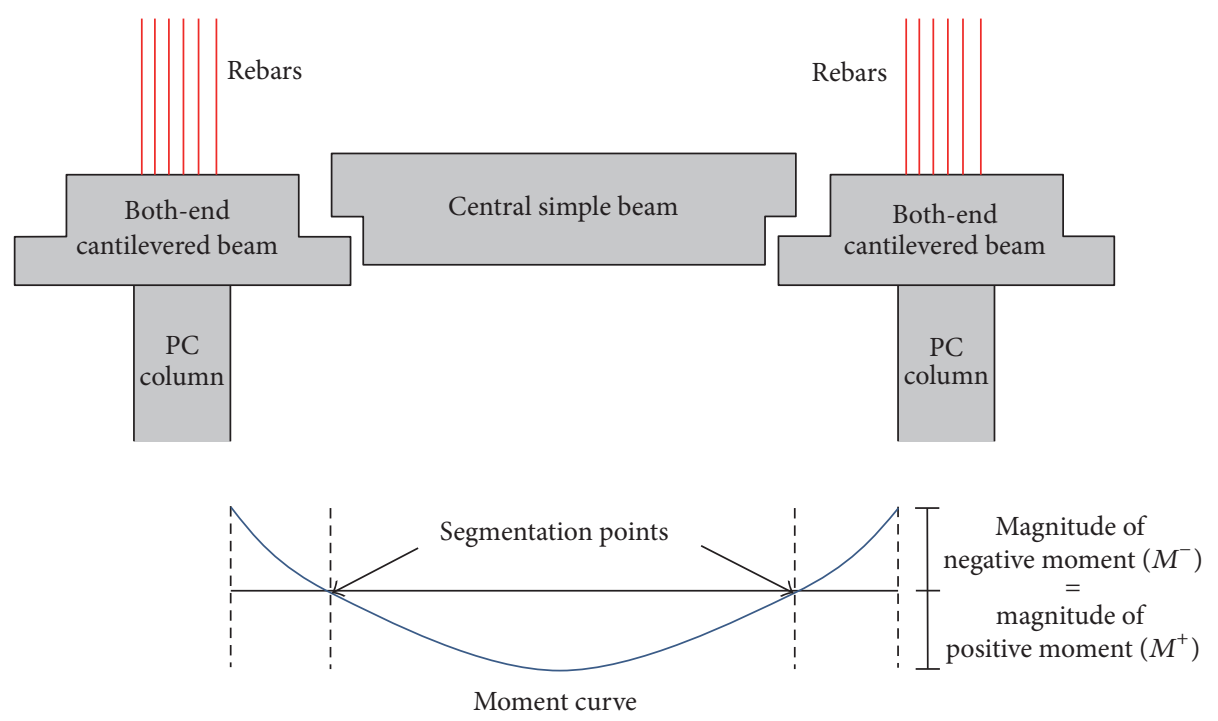

Figure 2: Concept of the segmented PC beam system and positions of segmentation points.

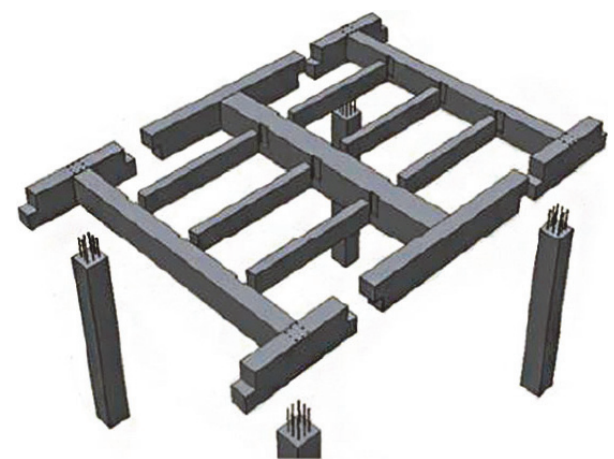

Figure 3: An example of a segmented PC beam system.

exhaust ducts, cables, bus ducts, utility provision, and exhaust pipes. Since the FAB floor is where precision fabrication occurs, it requires high stiffness. Thus, small columns are densely located between the FAB and R/P floors. The main columns that support the FAB floor are arranged at relatively wide intervals. Moreover, to reduce the time needed for construction, the FAB floor and small columns had steelframe structures, while the $\mathrm{R} / \mathrm{P}$ floor and main column employed structure systems constructed with PC.

In order to resolve the restriction posed by the traffic laws and to realize span lengths of $17 \mathrm{~m}$ and greater, the Gerber beam system with segmented PC method applied is applied to the R/P floor, as shown in Figure 2. By placing the cantilevered PC beam on top of the column and connecting the central PC beam to both ends of the cantilevered PC beam, this enables a structure with a large span length of $17 \mathrm{~m}$ or more. The floor structure plan of the R/P floor was constructed by segmenting the girder in the longitudinal direction as shown in Figure 3, and the remaining members smaller than or equal to $15 \mathrm{~m}$ in length were fabricated into single members and constructed.
The magnitudes of the positive and negative moments of the continuous beam under the gravity loads vary depending on the positions of segmentation points. Since the cross-sectional size of a beam is generally determined by the magnitudes of moments, the cross-sectional size of a segmented beam can be decreased by controlling the positions of segmentation points. For this reason, it is recommended that segmentation points are positioned where the magnitudes of the positive and negative moments of the continuous beam are same or similar as shown in Figure 2 to reduce the magnitudes of moments.

\section{Law of Similarity}

Although an experimental test on a real-size structure is the most accurate method of identifying and analyzing the vibration characteristics of a structure, it is not effective when considering the spatial limitations and costs involved, so generally a scale model is manufactured and experimented on. Defining the accumulation effect on a real structure as a physical ratio is known as the law of similarity, and this law is commonly applied to scale model experiments [24].

The law of similarity determines the physical value sought from the experiments based on dimensional analysis. For a generic dynamics problem according to time, the basic dimensions of length $(L)$, mass $(M)$, and time $(T)$ are selected, while the remaining physical parameters are derived as a combination of the basic dimensions [24]. For example, when defining the scale factor of the real structure to the scale model as " $S$," the scale relationship between the two structures is derived as shown in Table 1.

In general, research on the dynamic experiments using law of similarity has been conducted, and most of the laws of similarity selected have been based on acceleration. However, using acceleration as the basis means that the scale factor for the mass becomes $S^{2}$ and the mass of the scale model is 
TABLE 1: Law of similarity.

\begin{tabular}{lcccc}
\hline Parameter & Range & \multicolumn{2}{c}{ Scale factor } \\
Time basis & $S$ & $S$ \\
Length & $L$ & Mass basis & $S$ & $S^{2}$ \\
Mass & $M$ & $S$ & 1 & $S^{0.5}$ \\
Time & $T$ & $S$ & $S$ & 1 \\
Acceleration & $L T^{-2}$ & $1 / S$ & $S^{2}$ & $S^{2}$ \\
Force & $M L T^{-2}$ & $S^{2}$ & $S$ & $S^{3 / 4}$ \\
Damping & $M T^{-1}$ & $S^{2}$ & 1 & $1 / S^{0.5}$ \\
Natural frequency & $T^{-1}$ & $1 / S$ & $S^{3}$ & \\
\hline
\end{tabular}

reduced to $S^{3}$. In order to compensate for these values, an additional mass has to be attached to the model. The scale factor of this study is $0.5(S=1 / 2)$ where the additional mass for the acceleration basis becomes equal to the mass of the scale model, making the manufacturing of the test specimen difficult.

With respect to using a time basis, there is an advantage in that the natural frequency of the original structure and the scale model can be the same, but the additional mass with regard to the scale factor $S$ becomes large, as in the case of the acceleration basis, which again makes it difficult to manufacture the test specimen. Therefore, in this study, a scale model with mass basis applied, so that no additional mass is necessary, is prepared for the experimentation.

\section{Experimental Vibration Performance Evaluation}

4.1. Test Specimen Preparation. In order to assess the vibration performance of the long-span segmented PC structure, a Segmented Model is manufactured as shown in Figure 4, and vibration experimentation is conducted. Meanwhile, a Nonsegmented Model by the conventional PC method is also manufactured under the same scale condition (mass basis, $S=0.5$ ), as shown in Figure 5. The conventional PC method applied high technology industrial facility is based on a $14.4 \mathrm{~m}$ span length facility structure which is designed as a plasma display panel (PDP) fabrication facility. Vibration experiments are conducted using the same conditions for both the Nonsegmented and Segmented Models, and the relative vibration performance of the long-span segmented PC structure is evaluated by comparing the experiment results. Table 2 shows the design specifications of the Nonsegmented and Segmented Models.

\subsection{Experiment Method}

4.2.1. Vibration Characteristics Testing Using Impact Load. First, in order to obtain the dynamic properties of the scaled models, such as natural frequency, impact testing was performed using an impact hammer. The experimental method involves measuring the response at a random location on the structure where an impact hammer is used to apply impact,

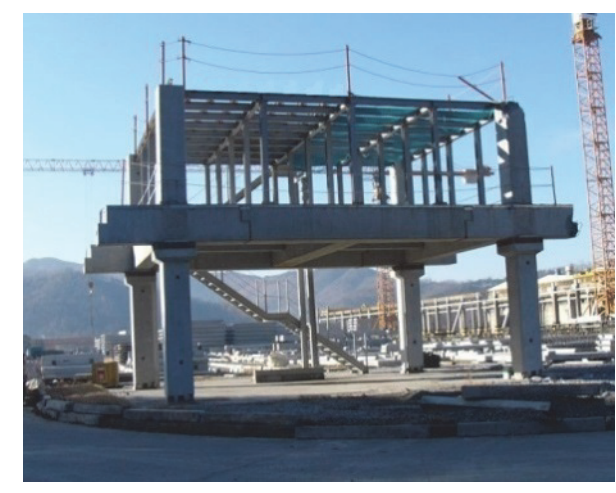

Figure 4: Test specimen photograph of Segmented Model.

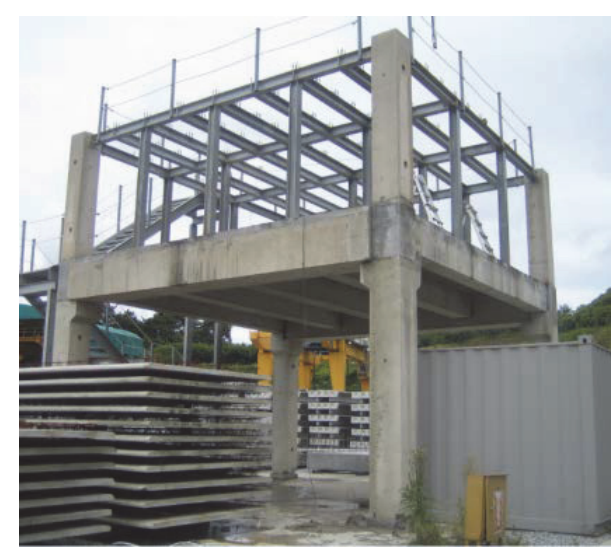

Figure 5: Test specimen photograph of Nonsegmented Model.

as shown in Figure 6. When an impact hammer excites the structure, the sensor in the impact hammer measures the impact force $f(t)$ and the accelerometer sensor installed at the location point intended to measure the response records the response $x(t)$ that is induced by the impact hammer. Impact force $f(t)$ and response $x(t)$ are data displayed in the time domain which can be shown in the frequency domain when (1) and (2) are used. Also, the response $X(\omega)$ and excitation force $F(\omega)$ defined in the frequency domain can be expressed as a linear relationship with the transfer function $H(\omega)$ as shown in (3). The transfer function $H(\omega)$ is a unique 
TABLE 2: Specifications of Nonsegmented and Segmented Models.

\begin{tabular}{|c|c|c|c|}
\hline & & Segmented & Nonsegmented \\
\hline \multirow{5}{*}{$\begin{array}{l}\text { Member dimensions } \\
\text { (unit: } \mathrm{mm} \text { ) }\end{array}$} & $\mathrm{R} / \mathrm{P}$ floor beam & $\begin{array}{l}500 \times 800 \\
250 \times 450 \\
650 \times 800 \\
700 \times 850\end{array}$ & $\begin{array}{l}400 \times 600 \\
350 \times 600 \\
700 \times 800\end{array}$ \\
\hline & Main column & $600 \times 600$ & $500 \times 500$ \\
\hline & FAB floor beam & $\mathrm{H}-200 \times 150 \times 6 \times 9$ & $\mathrm{H}-200 \times 150 \times 6 \times 9$ \\
\hline & Steel frame column & $\mathrm{H}-150 \times 150 \times 7 \times 10$ & $\mathrm{H}-150 \times 150 \times 7 \times 10$ \\
\hline & Slab & Thickness: 90 & Thickness: 90 \\
\hline \multicolumn{2}{|c|}{ Span } & $9000 \mathrm{~mm} \times 7500 \mathrm{~mm}$ & $7200 \mathrm{~mm} \times 7200 \mathrm{~mm}$ \\
\hline \multicolumn{2}{|c|}{ Story height } & $\begin{array}{l}\text { First floor: } 4500 \mathrm{~mm} \\
\text { Second floor: } 2750 \mathrm{~mm}\end{array}$ & $\begin{array}{l}\text { First floor: } 4500 \mathrm{~mm} \\
\text { Second floor: } 2750 \mathrm{~mm}\end{array}$ \\
\hline \multicolumn{2}{|c|}{ Material properties } & $\begin{array}{c}27 \mathrm{MPa} \text { concrete } \\
500 \mathrm{MPa} \text { rebar } \\
400 \mathrm{MPa} \text { section steel }\end{array}$ & $\begin{array}{c}27 \mathrm{MPa} \text { concrete } \\
500 \mathrm{MPa} \text { rebar } \\
400 \mathrm{MPa} \text { section steel }\end{array}$ \\
\hline
\end{tabular}

TABLE 3: Equipment specifications used in the vibration characteristics test.

\begin{tabular}{lcc}
\hline Equipment & Model & Function \\
\hline SignalCalc & Data Physics Co. & Vibration measurement \\
Mobilyzer & Model: DP440 & $\begin{array}{c}\text { and analysis system } \\
\text { Transfer function }\end{array}$ \\
Impact Hammer & Type 8210 & $\begin{array}{c}\text { measurement and mode } \\
\text { analysis }\end{array}$ \\
Accelerometer & Dytran 3191A & $\begin{array}{c}\text { Vibration measurement } \\
\text { precision sensor }\end{array}$ \\
Modal Analyzer & Star Modal Ver 5.1 & Natural frequency \\
\hline
\end{tabular}

property of the structure representing the magnitude of the response with respect to the unit excitation force. Table 3 shows the equipment specifications used in the vibration test.

$$
\begin{aligned}
& F(\omega)=\frac{1}{2 \pi} \int_{-\infty}^{\infty} f(t) e^{-j w t} d t \\
& X(\omega)=\frac{1}{2 \pi} \int_{-\infty}^{\infty} x(t) e^{-j w t} d t \\
& X(\omega)=H(\omega) F(\omega) .
\end{aligned}
$$

4.2.2. Response Experiment Using Harmonic Loads. High technology industrial facilities are excited by a variety of causes such as motors, impact, and human walking. However, it is realistically hard to set up vibration environment equivalent to the real vibration conditions at the scale experiment procedure. In this study, among the various exciting causes, a motor is considered as the excitation force, and the resulting responses of two scale models are compared. There are a number of fabrication equipment and air conditioning equipment operated by motors on the FAB and R/P floors. The power, voltage, and pole number of a motor employed in this study are $0.2 \mathrm{~kW}, 380 \mathrm{~V}$, and $2 \mathrm{P}$, respectively. The excitation frequencies of $20 \mathrm{~Hz}, 40 \mathrm{~Hz}$, and $60 \mathrm{~Hz}$ are employed.

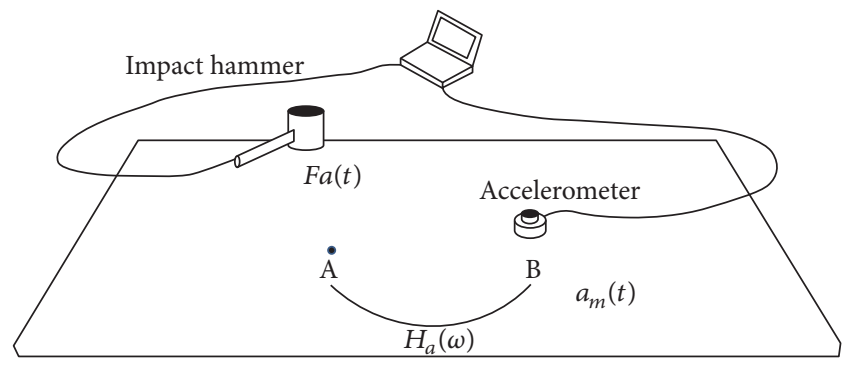

FIGURE 6: Impact hammer excitation experiment setup.

4.3. Results and Discussion. The excitation and measurement locations of two tests are shown in Figures 7-10. Since dimensions and plans of two models are different, excitation and measurement locations of two models are different. To compare the results between two models despite these differences, in this study, the averaged values are used.

The results from the impact test are shown in Tables 4 and 5 and Figure 11. The averaged results of the dynamic characteristics experiment for the FAB floor are summarized in Table 4 . The frequencies of the 1st, $2 \mathrm{nd}$, and $3 \mathrm{rd}$ resonance responses for the frequency domain are found to be $94 \%$, 93.9\%, and 91.5\%, respectively, for the Segmented Model when compared to the Nonsegmented Model. The results show that the resonance response of the Segmented Model occurs at a lower frequency domain than the resonance response of the Nonsegmented Model.

The magnitudes of the 1st, 2 nd, and 3rd resonance responses shown as the velocity value in the frequency domain are $54.2 \%, 55.8 \%$, and $78.9 \%$, respectively, for the Segmented Model when compared to the Nonsegmented Model. The response magnitude for the Segmented Model was significantly less than that of the Nonsegmented Model.

The averaged results of dynamic characteristics experiment for the R/P floor are summarized in Table 5. The averaged values of the 1st, $2 \mathrm{nd}$, and $3 \mathrm{rd}$ resonance responses of the Segmented Model are 96.4\%, 92.5\%, and 104.9\%, respectively, 


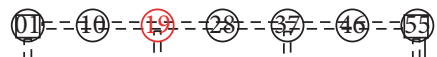

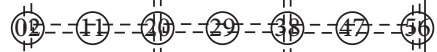

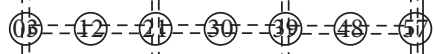

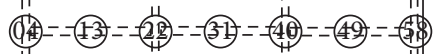

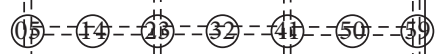

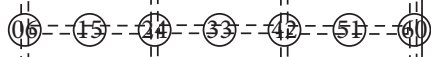

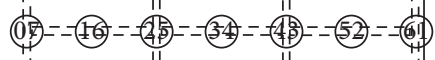

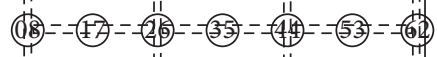

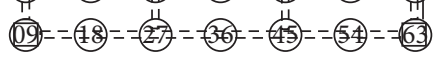
Excitation $\langle$ FAB floor $\rangle$

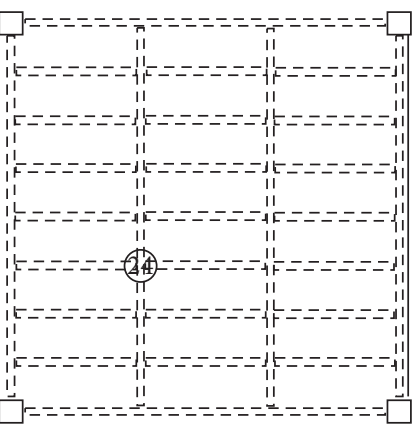

Measurement

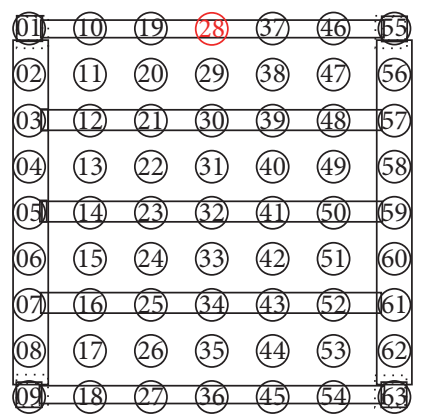

Excitation

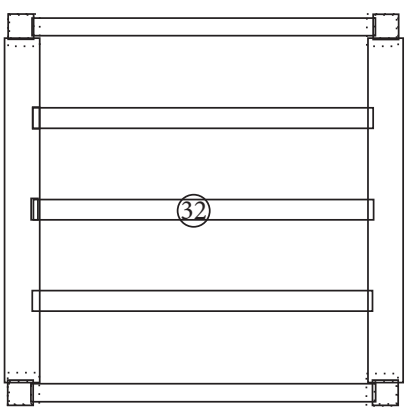

Measurement

$\langle\mathrm{R} / \mathrm{P}$ floor $\rangle$

FIgURE 7: Excitation and measurement locations in the impact test of Nonsegmented Model.

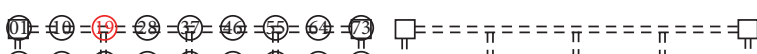

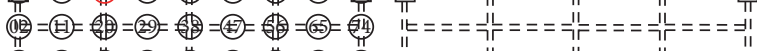

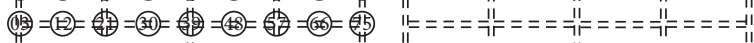

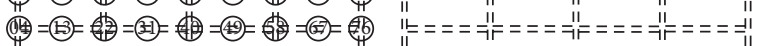

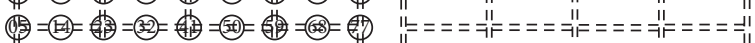

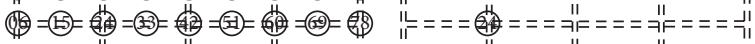

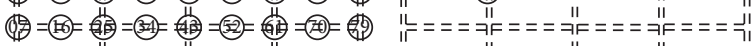

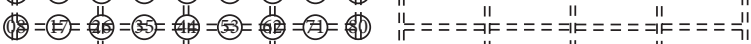

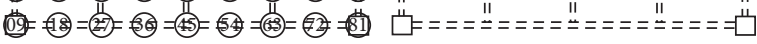
Excitation Measurement $\langle$ FAB floor $\rangle$

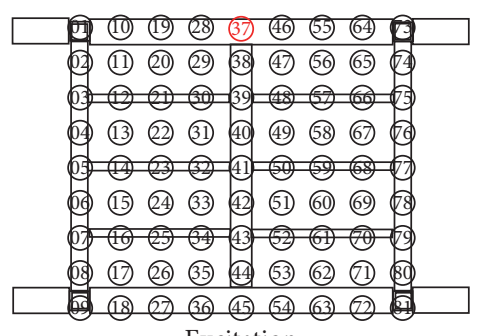
Excitation

$\langle\mathrm{R} / \mathrm{P}$ floor $\rangle$

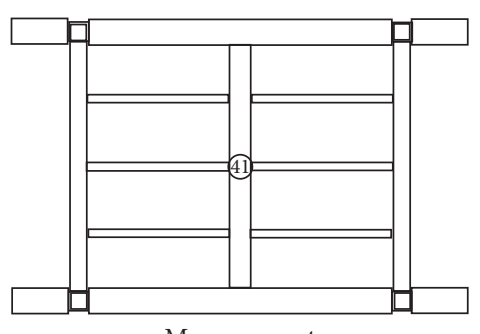

Measurement

FIGURE 8: Excitation and measurement locations in the impact test of Segmented Model.

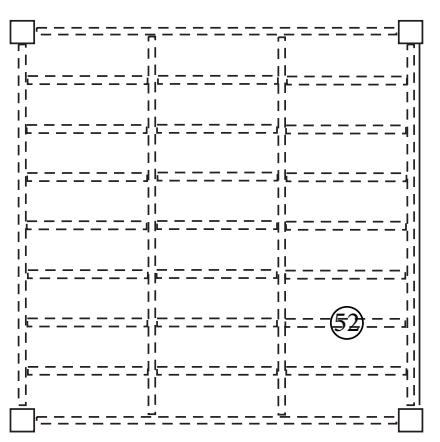

Excitation

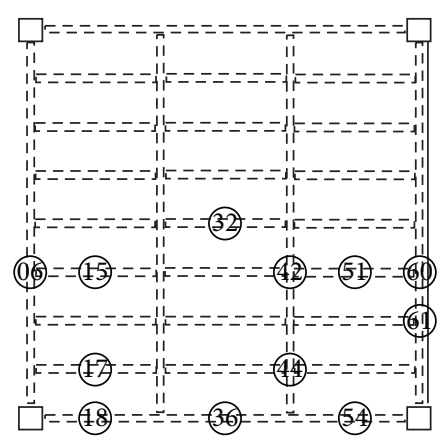

Measurement

$\langle$ FAB floor $\rangle$

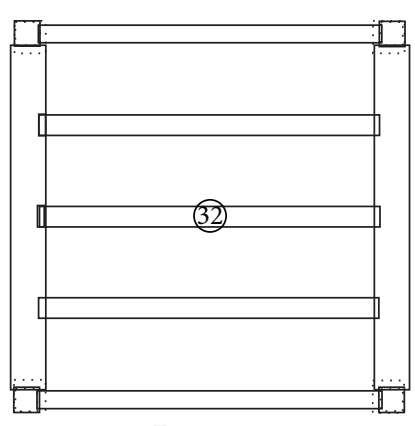

Excitation

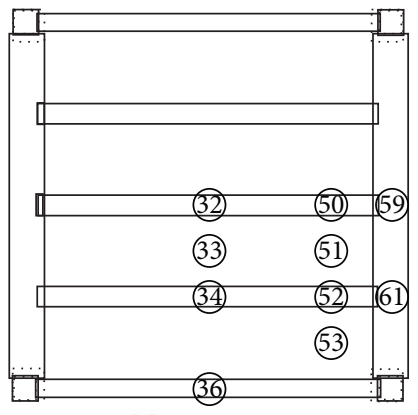

$\langle\mathrm{R} / \mathrm{P}$ floor $\rangle$

FIgURE 9: Excitation and measurement locations in the harmonic test of Nonsegmented Model.

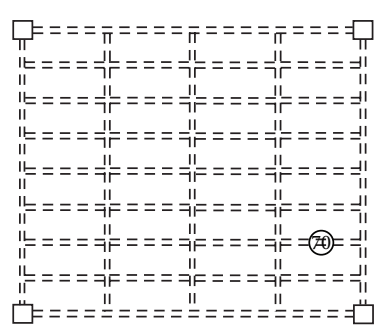

Excitation

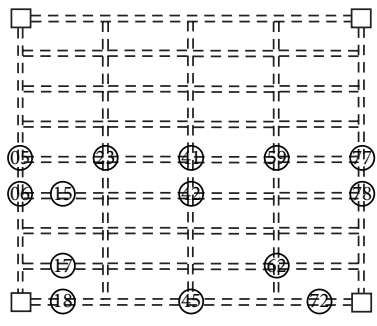

Measurement

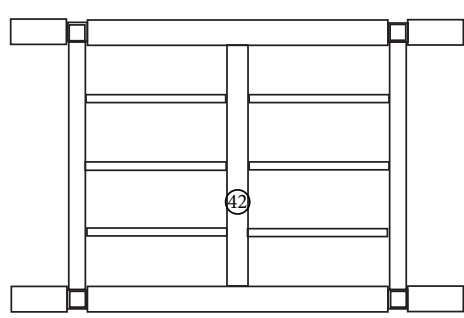

Excitation

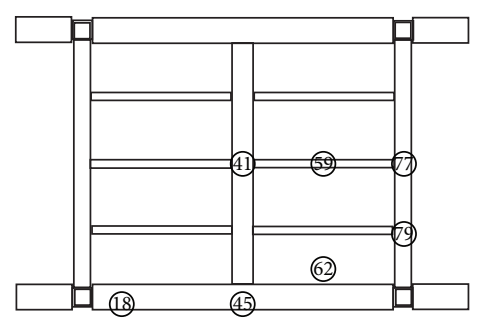

Measurement

$\langle$ FAB floor $\rangle$

$\langle\mathrm{R} / \mathrm{P}$ floor $\rangle$

FIgURE 10: Excitation and measurement locations in the harmonic test of Segmented Model. 


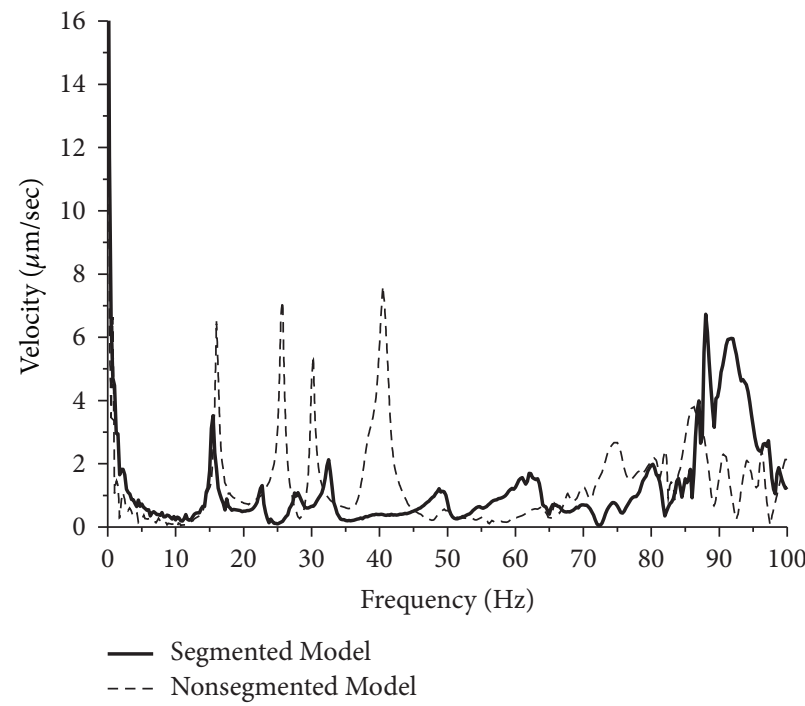

(a) FAB floor

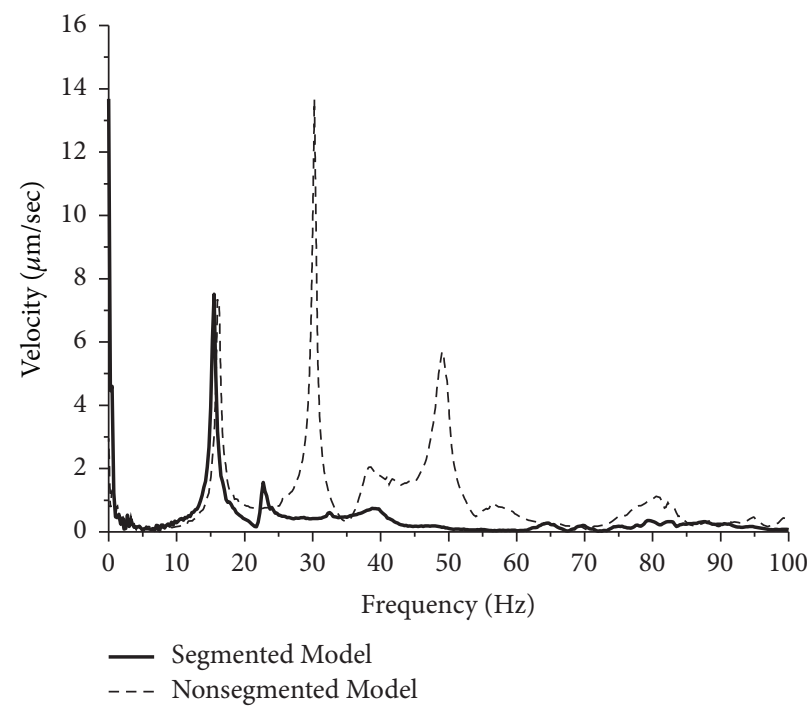

(b) R/P floor

FIGURE 11: Comparison of transfer functions of two models by the impact tests.

TABLE 4: Comparison of natural frequency and response magnitude by the impact test on FAB floor.

\begin{tabular}{|c|c|c|c|c|c|c|}
\hline \multirow[b]{2}{*}{ Mode } & \multicolumn{3}{|c|}{ Frequency $(\mathrm{Hz})$} & \multicolumn{3}{|c|}{ Response (um/Ns) } \\
\hline & $\begin{array}{c}\text { Nonsegmented } \\
\text { Model }\end{array}$ & $\begin{array}{l}\text { Segmented } \\
\text { Model }\end{array}$ & $\begin{array}{c}\text { Ratio } \\
(\%)\end{array}$ & $\begin{array}{c}\text { Nonsegmented } \\
\text { Model }\end{array}$ & $\begin{array}{c}\text { Segmented } \\
\text { Model }\end{array}$ & $\begin{array}{c}\text { Ratio } \\
(\%)\end{array}$ \\
\hline 1 st & 16.2 & 15.2 & 94.0 & 13.1 & 7.1 & 54.2 \\
\hline 2nd & 25.8 & 24.3 & 93.9 & 6.1 & 3.4 & 55.8 \\
\hline $3 \mathrm{rd}$ & 33.3 & 30.4 & 91.5 & 5.2 & 4.1 & 78.9 \\
\hline
\end{tabular}

TABLE 5: Comparison of natural frequency and response magnitude by the impact test on R/P floor.

\begin{tabular}{|c|c|c|c|c|c|c|}
\hline \multirow[b]{2}{*}{ Mode } & \multicolumn{3}{|c|}{ Frequency $(\mathrm{Hz})$} & \multicolumn{3}{|c|}{ Response (um/Ns) } \\
\hline & $\begin{array}{c}\text { Nonsegmented } \\
\text { Model }\end{array}$ & $\begin{array}{c}\text { Segmented } \\
\text { Model }\end{array}$ & $\begin{array}{c}\text { Ratio } \\
(\%)\end{array}$ & $\begin{array}{c}\text { Nonsegmented } \\
\text { Model }\end{array}$ & $\begin{array}{c}\text { Segmented } \\
\text { Model }\end{array}$ & $\begin{array}{c}\text { Ratio } \\
(\%)\end{array}$ \\
\hline 1 st & 16.3 & 15.7 & 96.4 & 13.5 & 6.3 & 46.3 \\
\hline $2 \mathrm{nd}$ & 29.1 & 26.9 & 92.5 & 4.9 & 0.9 & 17.8 \\
\hline $3 \mathrm{rd}$ & 38.6 & 40.5 & 104.9 & 3.5 & 0.8 & 23.8 \\
\hline
\end{tabular}

when compared with those of the Nonsegmented Model. The 1st and 2nd resonance responses of the Segmented Model occur in a somewhat low frequency range compared to the Nonsegmented Model while the 3rd response occurs in a somewhat high frequency range.

The magnitudes of the 1st, $2 \mathrm{nd}$, and $3 \mathrm{rd}$ resonance responses are $46.3 \%, 17.8 \%$, and $23.8 \%$, respectively, for the Segmented Model, revealing that the resonance response magnitudes of the Segmented Model are significantly lower than those of the Nonsegmented Model.

Figure 11 shows examples of transfer functions of the Nonsegmented Model and Segmented Model obtained from the impact tests. Figure 11 is made based on the results of impact tests that excitation locations for $\mathrm{FAB}$ and $\mathrm{R} / \mathrm{P}$ floors of Nonsegmented Model are 19 and 28 in Figure 7, respectively, and those for FAB and R/P floors of Segmented Model are 19 and 37 in Figure 8, respectively. Since the values in Tables 4 and 5 are the values averaging results from multiple impact tests while Figure 11 is based on the result from the specific impact test, the frequency values and peak responses can be different. It is confirmed that the response magnitudes of the Segmented Model tend to be smaller than those of the Nonsegmented Model.

The averaged results of harmonic tests are summarized in Table 6 . The averaged responses of FAB floor for the excitation frequencies of $20 \mathrm{~Hz}, 40 \mathrm{~Hz}$, and $60 \mathrm{~Hz}$ are $48.4 \%, 32.5 \%$, and $81.2 \%$, respectively. The averaged responses of $\mathrm{R} / \mathrm{P}$ floor for the excitation frequencies of $20 \mathrm{~Hz}, 40 \mathrm{~Hz}$, and $60 \mathrm{~Hz}$ are 
TABLE 6: Comparison of responses of two Models by the harmonic tests.

\begin{tabular}{|c|c|c|c|c|c|c|c|c|c|}
\hline \multirow{3}{*}{ Floor } & \multicolumn{3}{|c|}{ Response of Nonsegmented Model (um/Ns) } & \multicolumn{3}{|c|}{ Response of Segmented Model (um/Ns) } & \multicolumn{3}{|c|}{ Ratio (\%) } \\
\hline & \multicolumn{3}{|c|}{ Excitation frequency $(\mathrm{Hz})$} & \multicolumn{3}{|c|}{ Excitation frequency $(\mathrm{Hz})$} & \multicolumn{3}{|c|}{ Excitation frequency $(\mathrm{Hz})$} \\
\hline & 20 & 60 & 60 & 20 & 60 & 60 & 20 & 60 & 60 \\
\hline FAB & 21.9 & 210.8 & 740.5 & 10.6 & 68.5 & 601.3 & 48.4 & 32.5 & 81.2 \\
\hline $\mathrm{R} / \mathrm{P}$ & 20.4 & 825.5 & 415.4 & 9.2 & 277.8 & 94.6 & 45.1 & 33.7 & 22.8 \\
\hline
\end{tabular}

$45.1 \%, 33.7 \%$, and $22.8 \%$, respectively. It is confirmed that responses of Segmented Model are smaller than those of Nonsegmented Model.

\section{Conclusion}

In this study, to resolve the application limitation of the precast concrete (PC) method in high technology industrial facilities caused from the transport length restriction set by traffic laws, a structural system with a segmented PC system is introduced and the vibration performance of the segmented PC system is evaluated by the experimental test using the models scaled based on the mass basis law of similarity which does not require additional mass.

Using the mass basis law of similarity (scale factor $S=$ 0.5), a Segmented Model is manufactured using the segmented method to produce a width of $9000 \mathrm{~mm}$, depth of $7500 \mathrm{~mm}$, and height of $7250 \mathrm{~mm}$. In order to assess the relative vibration performance of the Segmented Model, a Nonsegmented Model is additionally manufactured, and the nonsegmented PC method, which is widely applied to conventional high technology industrial facilities, is applied to produce the Nonsegmented Model with a width of $7200 \mathrm{~mm}$, depth of $7200 \mathrm{~mm}$, and height of $7250 \mathrm{~mm}$. The cross-sectional dimension of a girder in the original structure $(14.4 \mathrm{~m} \times 14.4 \mathrm{~m})$ for Nonsegmented Model is $1400 \mathrm{~mm} \times$ $1600 \mathrm{~mm}$, and the cross-sectional dimension of a girder in the original structure $(18 \mathrm{~m} \times 15 \mathrm{~m})$ for Segmented Model is $1400 \mathrm{~mm} \times 1700 \mathrm{~mm}$.

Compared to the span length and the height of cross section of a girder of Nonsegmented Model, those of Segmented Model are increased by $25 \%$ and $6.25 \%$, respectively. The amount of increase in span length is larger the amount of increase in the dimension of cross section. This results in the decrease of stiffness of a structure. Although the stiffness of Segmented Model is smaller than that of Nonsegmented Model, it is shown that microvibration responses of Segmented Model at low frequency range are smaller than those of Nonsegmented Model. It is thought that the increased masses of Segmented Model compared to those of Nonsegmented Model affect responses. According to Newton's second law, if the magnitude of the applied force is same, the increased mass of the structure leads to the reduction in the response of the structure caused by the force.

\section{Competing Interests}

The authors declare that there is no conflict of interests regarding the publication of this paper.

\section{Acknowledgments}

This research was supported by Basic Science Research Program through the National Research Foundation of Korea (NRF) funded by the Ministry of Education (NRF2014R1A1A2059874).

\section{References}

[1] K. A. Salyards and R. J. Firman III, "Review of generic and manufacturer design criteria for vibration-sensitive equipment," in Proceedings of the 27th Conference and Exposition on Structural Dynamics (IMAC XXVII), Society for Experimental Mechanics (SEM), Orlando, Fla, USA, February 2009.

[2] E. E. Ungar, D. H. Sturz, and C. H. Amick, "Vibration control design of high technology facilities," Sound and Vibration, vol. 24, no. 7, pp. 20-27, 1990.

[3] H. Amick, "On generic vibration criteria for advanced technology facilities: with a tutorial on vibration data representation," Journal of the Institute of Environmental Sciences, vol. 40, no. 5, pp. 35-44, 1997.

[4] C. G. Gordon, "Generic criteria for vibration-sensitive equipment," in Vibration Control in Microelectronics, Optics, and Metrology, vol. 1619 of Proceedings of SPIE, pp. 71-85, International Society for Optical Engineering (SPIE), February 1991.

[5] H. Amick, M. Gendreau, and C. G. Gordon, "Facility vibration issues for nanotechnology research," in Proceedings of the Symposium on Nano Device Technology, Hsinchu, Taiwan, 2002.

[6] H. Amick, M. Gendreau, T. Busch, and C. G. Gordon, "Evolving criteria for research facilities: vibration," in Buildings for Nanoscale Research and Beyond, vol. 5933 of Proceedings of SPIE, September 2005.

[7] C.-L. Lee, Y.-P. Wang, and R. K. L. Su, "Assessment of vibrations induced in factories by automated guided vehicles," Proceedings of the Institution of Civil Engineers-Structures and Buildings, vol. 166, no. 4, pp. 182-196, 2013.

[8] T.-C. Pan, X. You, and C. L. Lim, "Evaluation of floor vibration in a biotechnology laboratory caused by human walking," Journal of Performance of Constructed Facilities, vol. 22, no. 3, pp. 122-130, 2008.

[9] J. M. W. Brownjohn, T.-C. Pan, C. Middleton, S. C. Tan, and G. Yang, "Floor vibration serviceability in a multistory factory building," Journal of Performance of Constructed Facilities, vol. 30, no. 1, Article ID 04014203, 2016.

[10] M. Ismail, J. Rodellar, and F. Ikhouane, "An innovative isolation bearing for motion-sensitive equipment," Journal of Sound and Vibration, vol. 326, no. 3, pp. 503-521, 2009.

[11] Y. L. Xu, Z.-F. Yu, and S. Zhan, "Experimental study of a hybrid platform for high-tech equipment protection against earthquake and microvibration," Earthquake Engineering and Structural Dynamics, vol. 37, no. 5, pp. 747-767, 2008. 
[12] Y. L. Xu, Z. C. Yang, J. Chen, H. J. Liu, and J. Chen, "Microvibration control platform for high technology facilities subject to traffic-induced ground motion," Engineering Structures, vol. 25, no. 8, pp. 1069-1082, 2003.

[13] Y. L. Xu and A. X. Guo, "Microvibration control of coupled high tech equipment-building systems in vertical direction," International Journal of Solids and Structures, vol. 43, no. 21, pp. 65216534, 2006

[14] E. I. Rivin, "Vibration isolation of precision equipment," Precision Engineering, vol. 17, no. 1, pp. 41-56, 1995.

[15] Y. Q. Ni, Z. G. Ying, and Z. H. Chen, "Micro-vibration suppression of equipment supported on a floor incorporating magneto-rheological elastomer core," Journal of Sound and Vibration, vol. 330, no. 18-19, pp. 4369-4383, 2011.

[16] H. P. Gavin and A. Zaicenco, "Performance and reliability of semi-active equipment isolation," Journal of Sound and Vibration, vol. 306, no. 1-2, pp. 74-90, 2007.

[17] H. Amick, S. Hardash, P. Gillett, and R. J. Reaveley, "Design of stiff, low-vibration floor structures," in Vibration Control in Microelectronics, Optics, and Metrology, Proceedings of SPIE, pp. 180-191, International Society for Optics and Photonics, February 1992.

[18] A. Pavic and P. Reynolds, "Vibration serviceability of long-span concrete building floors. Part 1: review of background information," Shock and Vibration Digest, vol. 34, no. 3, pp. 191-211, 2002.

[19] C. J. Middleton and J. M. W. Brownjohn, "Response of high frequency floors: a literature review," Engineering Structures, vol. 32, no. 2, pp. 337-352, 2010.

[20] C. Q. Howard and C. H. Hansen, "Vibration analysis of waffle floors," Computers and Structures, vol. 81, no. 1, pp. 15-26, 2003.

[21] KICT, Development of the Prefabricated System of the RC Building Structures, Korea Institute of Civil Engineering and Building Technology, Goyang, Republic of Korea, 1999.

[22] S. S. Lee, H. M. Chun, J. G. Kim, and K. Hong, "Suggestions of segmented PC frame systems for the long span floor of antivibration industrial buildings," Journal of Architectural Institute of Korea (Structural Division), vol. 26, no. 11, pp. 13-20, 2010.

[23] H. J. Cowan and P. R. Smith, Dictionary of Architectural and Building Technology, Spon Press, New York, NY, USA, 4th edition, 2004.

[24] H. Harris and G. Sabnis, Structural Modeling and Experimental Techniques, CRC Press, 2nd edition, 1999. 


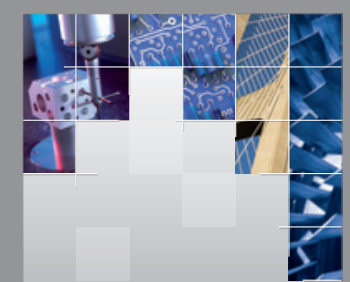

\section{Enfincering}
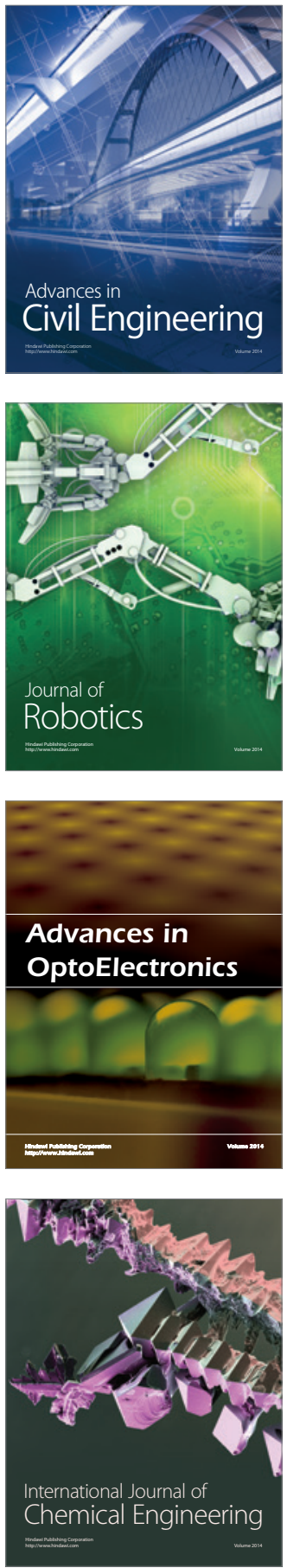

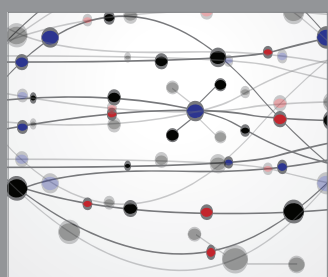

The Scientific World Journal

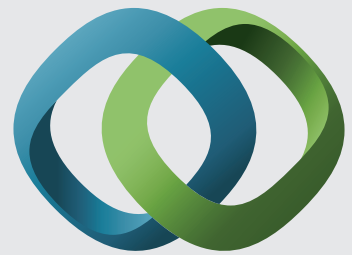

\section{Hindawi}

Submit your manuscripts at

https://www.hindawi.com
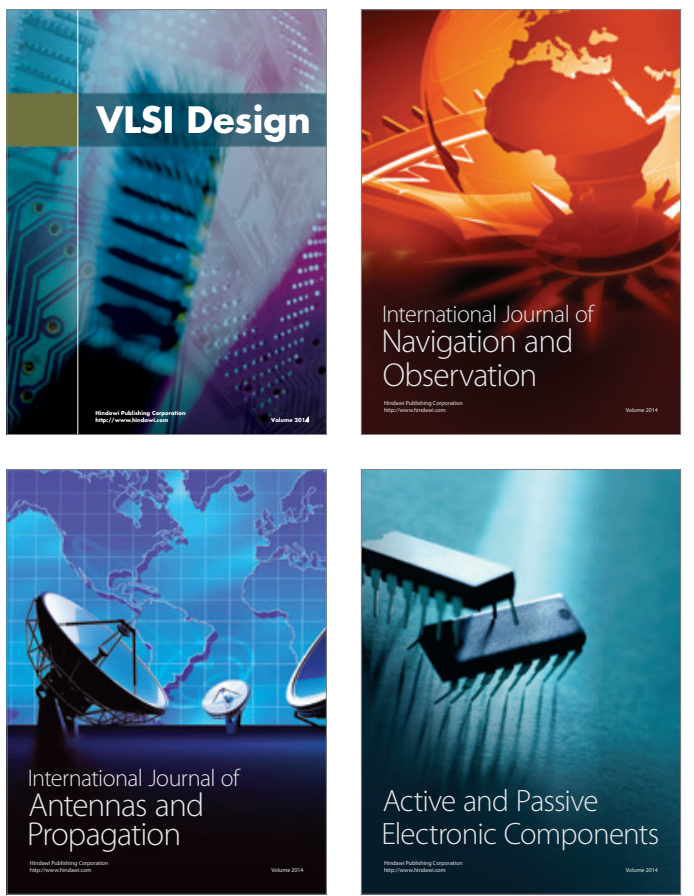
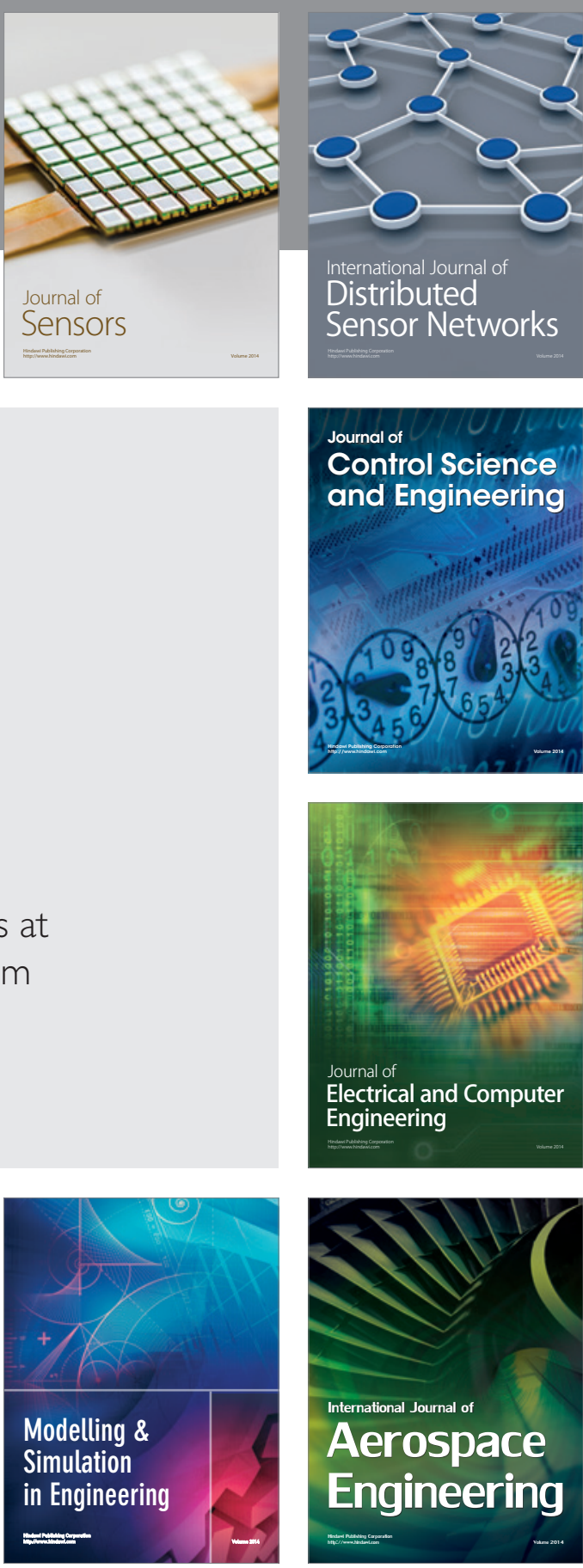

International Journal of

Distributed

Sensor Networks

$-$

Joumal of

Control Science

and Engineering
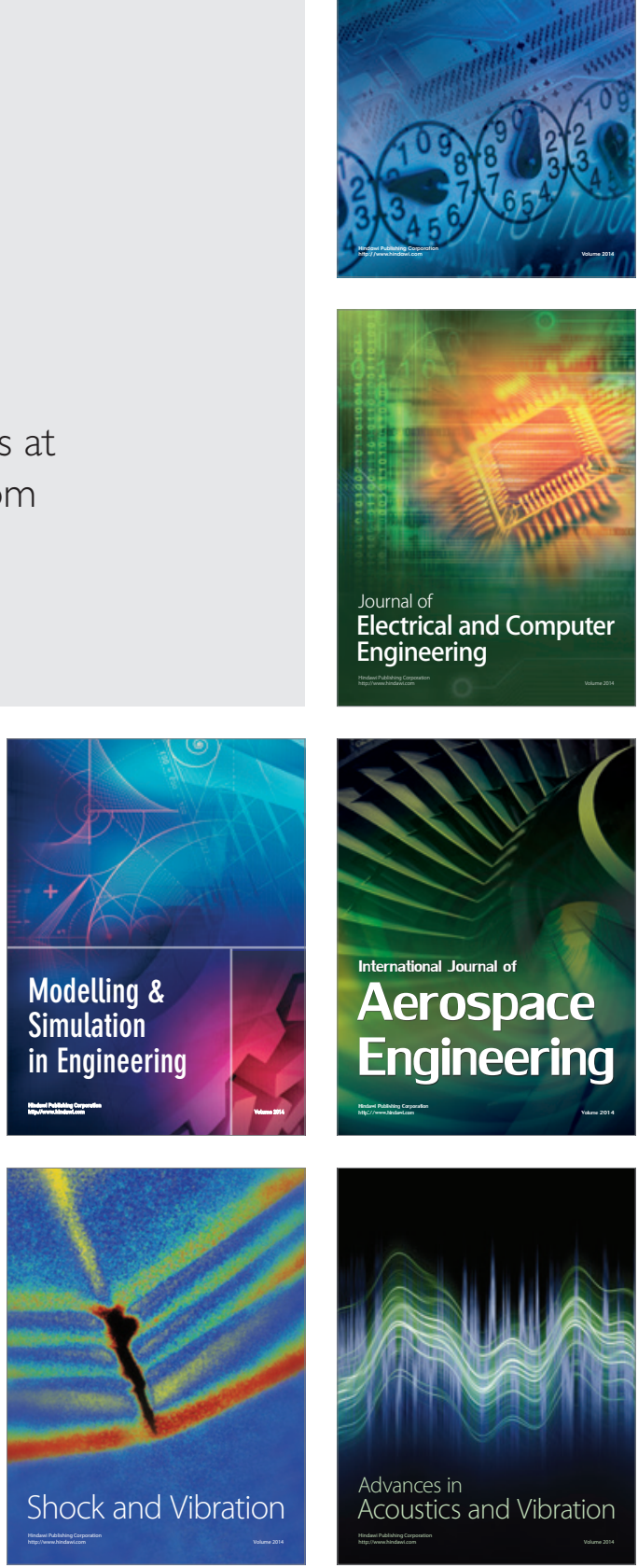